"President. No, no, not called upon : no one is called upon to speak-no one need speak unless they please.

"Mr. Murchison. Very well, Mr. President, then I am commissioned by the gentlemen whom you have not called upon to say that they are not at present prepared with arguments to refute Dr. Buckland's theories but probably may wish to do so at some future time."

Dr. Boase then stood forth, and began " in a very angry tone" by saying that he had "not been beaten down by Dr. Buckland's speech ", and Sedgwick and Murchison had both to assure him that they had never intended to suggest this (and indeed it was sufficiently obvious from what remains to us of the speaker's diatribe). Phillips then took up Whewell's theory of segregation, and by way of supporting it, remarked rather caustically that " he would venture to trespass so far on the attention of the meeting as to state the facts distinctly ". One faintly conceives Whewell's own sentiments on hearing this; but the meeting now appears to have concluded peacefully.

The proceedings at the general meeting on the following day seem, however, to have been even less harmonious. It opened, following a practice of the time, with reports of sectional transactions by appropriate representatives ; and so far all was well. Then Peacock read a paper on the analysis of algebra, amid a buzz of conversation which Sedgwick vainly attempted to check : at last " the president requested that a constable should be sent up to stand by him " ; actually, " a servant" was procured. Sedgwick by this time may have been feeling the strain of his office : he " observed that Professor Henslow had some proposal which he wished to make to the meeting and he had better speak for himself, as he considered that Professor Henslow knew his own intentions better than he, for he could not understand them at all ". Poor Professor Henslow had nothing less innocent to propose than a botanical excursion. " $\mathrm{He}$ believed the neighbourhood of Cambridge furnished little matter interesting to the geologist, or no doubt Professor Sedgwick would have been happy to-_ Professor Sedgwick: Talk of your own affairs if you please, Professor Henslow, and do not interfere with my business." The upshot was that the president, ex cathedra, said in effect that the botanists could do as they liked, but if the geologists wanted an excursion, he would rather be excused.

Certain further papers were given, including one by Rennie on hydraulics, " much too learned for common comprehension, and not well read". Finally, the president took the floor with a series of announcements, about "the ordinary", about a display of fireworks which " every member was invited to see and take with him a train of three ladies ", about a recondite jest of Whewell's concerning waterworks in place of the fireworks; and at last "after several times calling the assemblage back to hear different announcements which he had forgotten, the meeting broke up for that day".

Such, we must suppose, is the earliest attempt to provide brighter reports of the meetings. One suspects that the "Mudfog Papers" may have had some basis in reality.

\title{
Physical Laboratories and Social Service*
}

\section{By Sir William BragG, O.M., K.B.E., F.R.S.}

$\mathrm{I}^{\mathrm{N}}$ these days the services to be rendered by a physical laboratory become more definite than they were: not more stereotyped, because the possibilities and modes of their usefulness are increasing, but more clearly understood. With some curiosity I have read again an address which Lord Kelvin (then Sir William Thomson) gave at the opening of the physical and chemical laboratories at University College in Bangor in 1885. Thomson could then describe, as happenings of his own time, the beginnings of instruction in practical physics and chemistry and the construction of the necessary laboratories. Soon after he went to Glasgow, in 1846, he was in need of help with some electrical measurements and invited the aid of students, which was willingly given. Others heard that some of their fellows had got experimental work to do, and begged to be allowed to join in. This was the beginning of practical work for the students in his laboratories. Thomson recalled, with great zest, that three-quarters of his helpers were theological students, and that he had to explain to an amazed outsider that they seemed to be happy in their work and were getting on very well.

* From an address delivered at the opening of the new Physics Building of the University of Leeds on Feb. 18.
At that time, of course, experimental science had already an accepted place, but there is a quaint evidence of a certain antagonism to it when he carefully explains that to measure the forms and properties of crystals is not to put them to an ignoble use.

At that time, also, the Cavendish Laboratory at Cambridge had got well under way; there were laboratories in the London colleges and elsewhere. But the number was small in comparison with that of to-day, when so many universities, colleges, schools, industrial firms, and other bodies have built and equipped laboratories, many of them magnificent in their equipments and their spaces. The nation itself has felt the need, and in 1899 founded the National Physical Laboratory at Teddington, where, also, a National Chemical Laboratory has now been working for the last few years. The research associations working in connexion with the Department of Scientific and Industrial Research have all their separate laboratories where physical and other research is carried on.

There has, in fact, been a great change since Thomson made his Bangor speech, in the general estimate of what may and ought to be expected from the physical laboratory. People are undoubtedly more interested in the growth of natural 
knowledge, and more aware of what it means to them. The manufacturer has discovered the possible, and often immediate, advantage of research; the politician observes that scientific discovery is a world force; the teacher and the thinker find that the unfolding of Nature's laws alters the lines on which they move, and many people of every kind ponder over what this continual advance in knowledge may imply.

Moreover, John Citizen is interested in yetanother way. There was once a time when private liberality alone founded institutions of learning and provided for their maintenance. Universities, colleges, and schools still owe much to the generosity of their friends. But such institutions are also, in these democratic days, supported directly by the citizen by way of government grants, county grants, municipal grants, and by more widely spread contributions from individuals. Industrial laboratories and State laboratories, of course, are directly provided for by funds which are expected to be repaid in the form of contributions to the welfare of industries and of the community in general. John Citizen has not only become interested as a spectator, in the advance of knowledge by experiment : he has also begun to see its advantage to himself, and is willing to pay for it.

Physics might be thought to be one of the last of the sciences to feel this change of attitude, because it is one of the most fundamental, further away than the others from direct contact with everyday life. Much of modern physics has, of course, an appearance of remoteness. That is not only due to the nature of the subject, but also because various applications of physics have led to hiving-off processes. As soon as a branch of physics becomes useful, it ceases to be physics and begins a new life under another name, such as the various forms of engineering science, or meteorology, or cryogenic research. But there are few things more fascinating in scientific work than the unexpected application of some discovery, made in the progress of a research which seems to be out of touch with everyday things: it may take the form of an illumination of some common event, or a solution of a vexed question, or a welcome aid in some enterprise. Contact is continually being made between the abstruse and the obvious: we should scarcely expect otherwise if we are convinced of an allembracing unity.

Thus a physical laboratory takes its recognised place of service to the community. What can it do now? How can it extend its service in the future?

First, of course, it exists for the instruction of the student. Many professions for which men and women are trained depend to a greater or lesser extent upon physical laws, which must be grasped and understood. Teaching by experiment can be made an instrument for most valuable training in accuracy, judgment, and the regard for unbiased opinion. Moreover, these young people go out into the world as exponents of ideas and principles which they have learnt to believe in. The great and useful influence which may proceed from a laboratory cannot, in general, be exerted directly : it has to be disseminated through many channels. In the laboratory it is possible to teach what science is, and what it implies: lessons which are far from being learnt by the world at large. The British Broadcasting Corporation, in its useful, praiseworthy way of attacking the great questions of the day, has recently employed eminent thinkers and workers to speak on "Science and Civilisation". These discourses have been, it seems to me, of great benefit to the cause of science, and not least those which at first sight seem to be antagonistic : for their ' acid' has bitten, not into science itself, but into false conceptions of it, and has left the nobler metal clean and untouched. There are two notable errors which discussions such as these help to remove. One is to mistake mechanisation for science, and to ascribe certain evils to science which come from a wrong use of the machine-which are in truth, as Sir Oliver Lodge says, a blot, not on science, but on civilisation. Splendid truths can be put to evil purposes. The other of the errors to which I would refer is the use of scientific terms, conceptions, and facts in regions where they have no place. I do not mean only arguments about ethers, vibrations, influences, and the like, which few people take seriously; but there is a curious liking for risky extrapolation ; for discussions of questions to which experimental science is not yet ready, possibly never will be ready, to give an answer ; for argument by analogy, which is dangerous.

A laboratory exists also for the increase of natural knowledge by experiment: and none more obviously so than the laboratory of a university. Of necessity, the most fundamental and valuable research must be done-not as being useless, as some exaggerations would have it--but without regard to the nature, or even the possibility of its use : which is obvious enough. I need not elaborate this vital point : it is well understood.

Of recent years the encouragement of industrial research has led to the establishment of a number of laboratories attached to various industries, and dealing mainly with the physical and chemical problems that industry encounters. These are supplied with men mainly trained in university laboratories. The Department of Scientific and Industrial Research makes a number of grants each year to men working in university laboratories in order that they may be enabled to train themselves for industrial research posts. It is for the university laboratory to encourage and help those who avail themselves of these grants. The university laboratory should be in touch with the surrounding research associations, thus keeping contact between pure science and its special adaptations.

It is possible that there is yet another way in which the laboratory may be of service. I mention it rather as a provocative suggestion than as an actual recommendation. Is it not possible to see more of John Citizen himself in the laboratory? Of late years the science museum has advanced in popularity and usefulness by leaps and bounds. It is far more up-to-date in its exhibits, far more interesting in its displays. The well-organised Science Museum in South Kensington is visited by 
far more than a million people a year. A huge museum is in course of erection in Philadelphia. The great museum in Munich is famous. It is, by the way, interesting that this pioneering institution should have been founded in the city where Count Rumford served the State of Bavaria so notably. For it was he who conceived the idea of the science museum and wrote elaborately on its objects and its management. This was a hundred and thirty years ago : and it could not be improved upon now. The Royal Institution was founded in the attempt to give form to his ideas. It failed to do so because the times were not ripe; but that is no longer the case. The Faraday Exhibition of last September drew fifty thousand visitors in the ten days of its activity. I had occasion recently to visit a smaller but similar exhibition arranged in the new laboratories at Exeter ; five thousand people visited it in two or three days. The public has not only a newly wakened interest in science, but also is delighted to see actual demonstrations. This is all the better because so much of the interest has been excited by written description or by talks over the ether, and the visible example is much needed as a corrective.
Such exhibitions are of proved value, and may be extremely useful under the conditions of to-day. If any effort were made to follow examples set elsewhere, to demonstrate visually to John Citizen the slow unfolding of Nature's laws by patient research, the discovery of unsuspected beauties of order and adaptation, the origin of new conceptions of the universe, and, not least, the skilful handling of new knowledge for the service and delight of man, then the university laboratories would naturally be looked to for help. To them it would fall, as it fell to the Royal Institution, to illustrate particularly the development of scientific ideas and methods.

We cannot ask that everyone shall be trained to understand and follow the advance of scientific knowledge. All that can be worked for-and it is far from our present attainment-is that there shall be an understanding of what science is, of what it can do, and of what it cannot do. Even this cannot be expected from the public as a whole: but it is urgently necessary in these days that a sufficient number shall be so informed, and especially those whose collective opinions and wishes determine the general courses of action.

\section{Clouds High in the Stratosphere}

\section{By Prof. S. Chapman, F.R.S.}

$\mathrm{T}^{\mathrm{H}}$ HREE years ago, Prof. C. Størmer, of Oslo, made a preliminary announcement in NATURE of photographic observations by himself and his assistants upon the height and colour-distribution of some clouds at a remarkably great height in the atmosphere nearly over Oslo. ${ }^{1}$ He has now issued a detailed account of this work, ${ }^{2}$ and also of some hitherto unpublished visual observations on similar clouds, made by him on Jan. 1 and Jan. 15, 1890. The memoir is very fully illustrated by 140 diagrams and eleven beautiful photographs, three of which are reproduced herewith.

The clouds were of the type termed in English iridescent; in German, the language in which Prof. Størmer's memoir is written, they are called Perlmutterwolken (mother-of-pearl clouds). The simile appears to be an apt one for the more luminous parts of the clouds, which present one of the most beautiful spectacles afforded by the sky. The colours and colour changes observed in these clouds are stated to be "essentially different" from the ordinary iridescence often seen at the edges of thin clouds near the sun. They are also very different from the bluish whiteness of the luminous night clouds, at about $80 \mathrm{~km}$. height according to Jesse, which Størmer states have often been seen by him. Very detailed descriptions are given as to the changing colour distribution of the clouds, especially for those of January 1890 ; the colours are mainly arranged in bands following the outlines of the clouds, and these bands, and the outlines, in some cases change rapidly, so that before a sketch of them is completed the earlier part of the sketch no longer represents the form of that section of the cloud.

Apart from their extreme beauty, the clouds are distinguished for their great height; this was suspected by the late Prof. H. Mohn, who specially studied these clouds, but it was first definitely confirmed by Prof. Størmer in 1927, who was able, on Dec. 30, 1926, to take two pairs of simultaneous photographs of such clouds from his auroral stations at Oslo and Oskarsborg. The height found was between $26 \mathrm{~km}$. and $30 \mathrm{~km}$. The new photographic material for the clouds of Jan. 13, 1929, is much more ample, the number of pairs of photographs exceeding ninety. The heights then found lie between $23 \mathrm{~km}$. and $26 \mathrm{~km}$. The existence of clouds at this high level had never previously been established. Ordinary clouds are almost entirely confined to the troposphere, that is, below about $10 \mathrm{~km}$. These mother-of-pearl clouds are high up in the stratosphere.

Yet another peculiarity of these clouds is their rarity ; Prof. Størmer saw them in 1890 , but from 1892 until the end of 1926 , though carefully watching for them, he failed to find any. In 1929 he again saw them. The conditions under which they were seen were similar in the three cases, and agreed with those described by Mohn, as associated with nearly all his observations of the clouds. They occur when there is a deep barometric depression near Oslo, and usually to the north; owing to the distribution of the mountains in the adjacent region, warm dry winds (Föhn) then often blow down the southerly and easterly slopes towards Oslo, and produce high temperatures, and a clear sky, over a part of the cyclonic area which is usually overclouded. Hence Størmer suggests that the high clouds may in fact be common features in the stratosphere over the ascending part of cyclones, but usually invisible. If this

$$
\text { No. 3257, VoL. 129] }
$$

